\title{
Diastereoselective Total Synthesis of (+)-Raputindole A: An Iridium- Catalyzed Cyclization Approach
}

\author{
Juliana L. L. F. Regueira ${ }^{\psi, \dagger}$, Luiz F. Silva, Jr${ }^{\psi, \#}$, Ronaldo A. Pilli*,† \\ ${ }^{\psi}$ Institute of Chemistry, University of São Paulo (USP), CEP 05508-000 São Paulo, Brazil. "Institute of Chemistry, Univer- \\ sity of Campinas (UNICAMP), CEP 13083-970 Campinas, São Paulo, Brazil. "In memorian
}

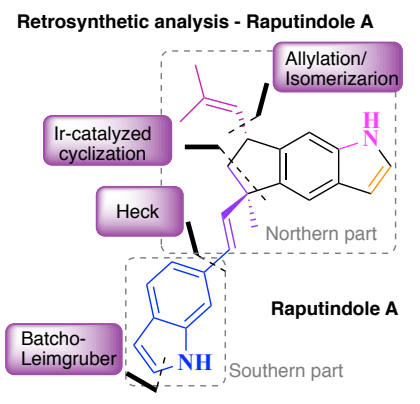

ABSTRACT: This work describes the total synthesis of Raputindole A (1) through a convergent approach which features: 1) an
iridium-catalyzed cyclization to assembly the tricyclic core of the northern part, 2) enzymatic resolution to secure the preparation of
enantiomerically pure benzylic alcohol, 3) installation of the butenyl substituent via methallylation of the corresponding benzylic
carbocation and coupling of the northern and southern parts via Heck reaction. (+)-Raputindole A (1) was prepared in 10 steps (LLS)
and $10 \%$ overall yield.

Raputindole A (1) was isolated in 2010, along with three isomers 2-4, from Raputia simullans kalunki, a tree found in the Peruvian amazon rainforest, and displayed moderate activity in the inhibition of CDK2, GSK-3B and DYRK1 kinases (IC50 > $10 \mathrm{uM})^{12}$. (figure 1). ${ }^{1}$ Deoxiraputindole $\mathrm{C} 5$ is another member of this class isolated from Raputia praetermissa. ${ }^{2}$ Structurally, this is a rare new class of indole alkaloids as it features unsubstituted N1, C2- and C3 positions. ${ }^{1}$ Other natural products containing this 1,2,3-unsubstituted pattern are trinkentrin $\mathrm{A}^{3}$ and the herbindole family ${ }^{4}$. Another feature of this rare alkaloid class is the presence of a linear tricyclic scaffold composed by an indane moiety fused to an indole ring as in shearinine $\mathrm{D}^{5}$ and in (+)-nodulisporic acid A. ${ }^{6} \mathrm{~A}$ third structural feature of raputindole A (1) is the presence of a bis-prenylated bisindole core as in the antimalarial alkaloids flinderoles $\mathrm{A}-\mathrm{C}^{7}$ which can conceivably be traced back to the cyclization of two isoprenyl groups. Other examples of bisindole alkaloids include the spongotine $\mathrm{A}^{8}$, caulindoles ${ }^{9}$ and dragmacidin $\mathrm{D}^{10}$ which, unlike raputindoles, have their indole moieties connected via C-3 (spongotine $\mathrm{A}$ and dragmacidin D) or via C-5 (caulindoles). ${ }^{11}$ In fact, the raputindoles attracted the attention of the natural products practioners. ${ }^{11}$ 


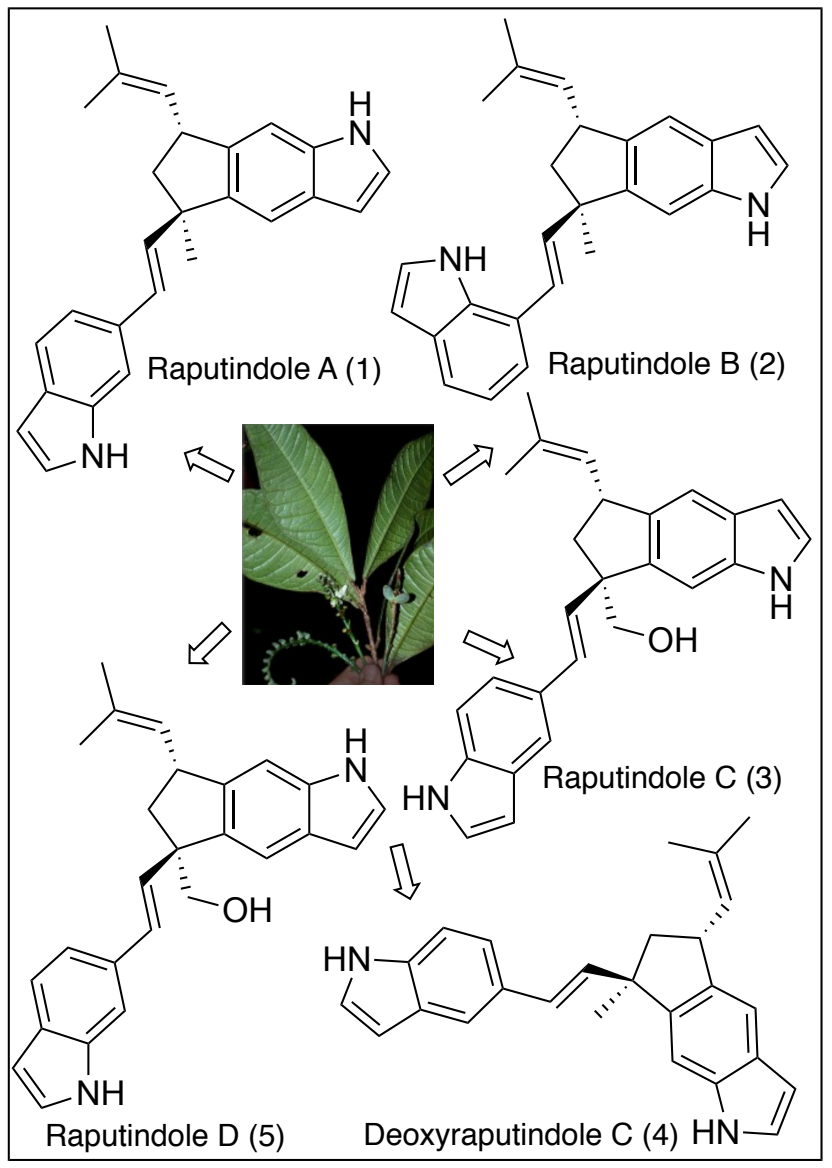

Figure 1. Members of the raputindole family. (Photo: Robin Foster, http://fieldmuseum.org/)

The absolute stereochemistry of raputindole A was determined in 2017 with the first total synthesis acomplished by Lindel and coworkers. ${ }^{12}$ Their synthetitc route involved an $\mathrm{Au}(\mathrm{I})$-catalyzed cyclization to access the linear tricycle and a Pd-catalyzed installation of the isobutenyl side chain. However low diastereoselectivity was observed in the indene catalytic hydrogenation to install the stereogenic center at C-7 and to solve this critical step, in 2018, the same group published a diastereoselective total synthesis of raputindole A (1).$^{13}$ In addition to the Au(I)-catalyzed assembly of the cyclopentaindole moiety, this second approach featured an iridium-catalyzed asymmetric hydrogenation of the indene double bond guided by a preinstalled hydroxyl function, a Suzuki-Miyaura cross coupling to join the two indole moieties and the final oxidation of the indoline precursor.

Our total synthesis of raputindole A (1) aimed to avoid the use of an indoline as a surrogate of the indole ring as it would require a late stage oxidation and of an indene intermediate as the precursor of the stereogenic center at C-7 to prevent the problems previously faced by Lindel and coworkers. Our strategy features the use of $N$-tosyl indoles in the northern and southern parts of the structure, an iridium-catalyzed diastereoselective cyclization $^{14}$ and a Heck cross coupling reaction to build the raputindole A (1) scaffold. It is noteworthy that our approach allows for the incorporation of an enzymatic resolution step which allows to obtain (+)-raputindole A (1).

Our disconnection relies on a convergent approach where the northern and southern parts are connected via a Heck coupling reaction (scheme 1). The isobutenyl side chain would be installed by allylation of tricyclic alcohol $\mathbf{6}$ with allyltrimethylsilane. ${ }^{15}$ The northern part would come from boronic acid 7, to be prepared from commercially available bromoindole $\mathbf{8}$. An iridium-catalyzed cyclization with isoprene would provide linear tricyclic indole 6, according to the methodology described by Hayashi and coworkers for representative boronic acids. ${ }^{14}$ The southern part required the preparation of indole 9 via a Batcho-Leimgruber protocol. This convergent approach could also allow for the total syntheses of raputindole $\mathrm{B}$ and deoxiraputindole $\mathrm{C}$ as well.

Scheme 1. Retrosynthetic analysis of Raputindole A (1).

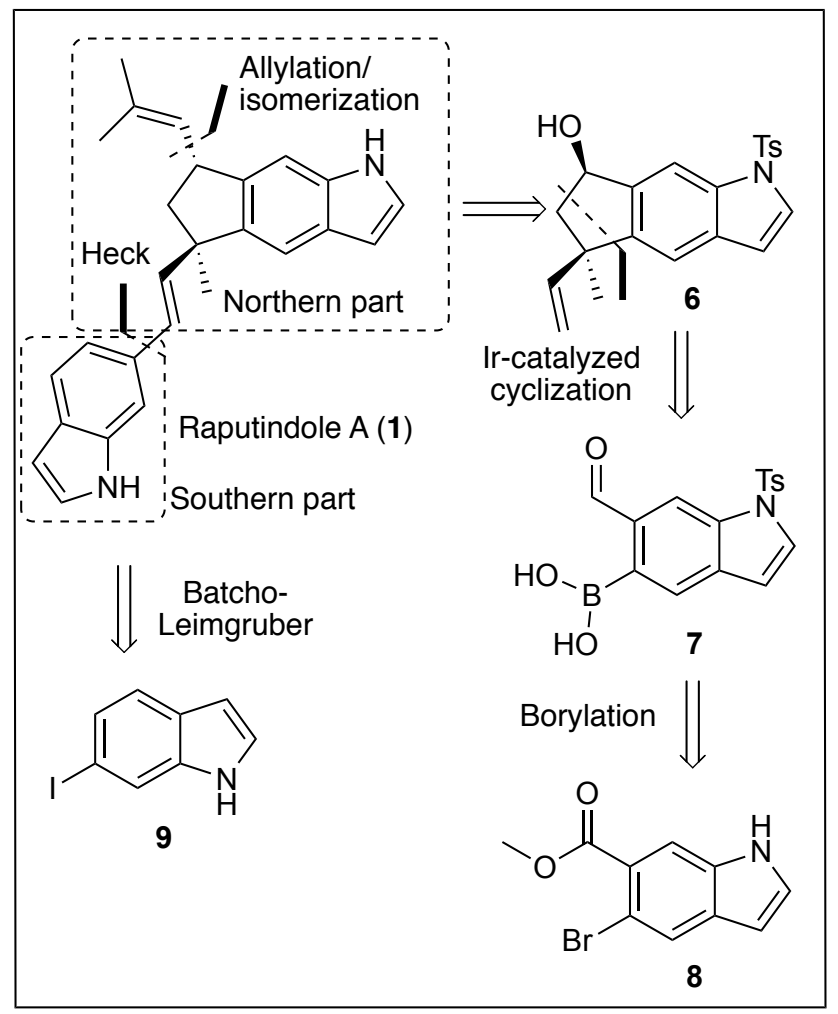

Commercially available 5,6-substituted indole $\mathbf{8}$ was protected as the corresponding $\mathrm{N}$-tosyl derivative in order to 8 en route to aldehyde $\mathbf{1 0}$ which involved $N$-tosylation, DIBAL-H reduction of the methyl ester and benzylic oxidation with manganese dioxide (3 steps, 95\% overall yield) (scheme 2). At this stage, to install the necessary boronic acid a Miyaura borylation was put in place using $\mathrm{Pd}(\mathrm{Cl})_{2}(\mathrm{ddpf})$ and bis(pinacolate)diboron which provided pinacol ester 11, in 95\% yield after silica gel chromatography. ${ }^{16}$ In 2007, Hayashi and coworkers disclosed an iridium-catalyzed [3+2] annulation of dienes with ortho-carbonylated phenylboronic acids. ${ }^{14}$ We decided to apply this methodology for the first time to the total synthesis of a natural product. Initial attempts to use the boronic acid $\mathbf{7}$ as the substrate in this cyclization provided at the most indole 6 in 36\% yield, and we decided to explore the in situ generation of boronic acid 7 via hydrolysis of pinacol ester $\mathbf{1 1}$ in the reaction medium. When we kept the reaction mixture in the dark, this one-pot approach proceeded regio- and stereoselectively to provide racemic linear tricyclic indole $c i s-6$, in $94 \%$ yield, as the key synthetic intermediate in our approach. ${ }^{17}$

Scheme 2. Iridium-catalyzed preparation of linear tricyclic indole (+/-)-6. 


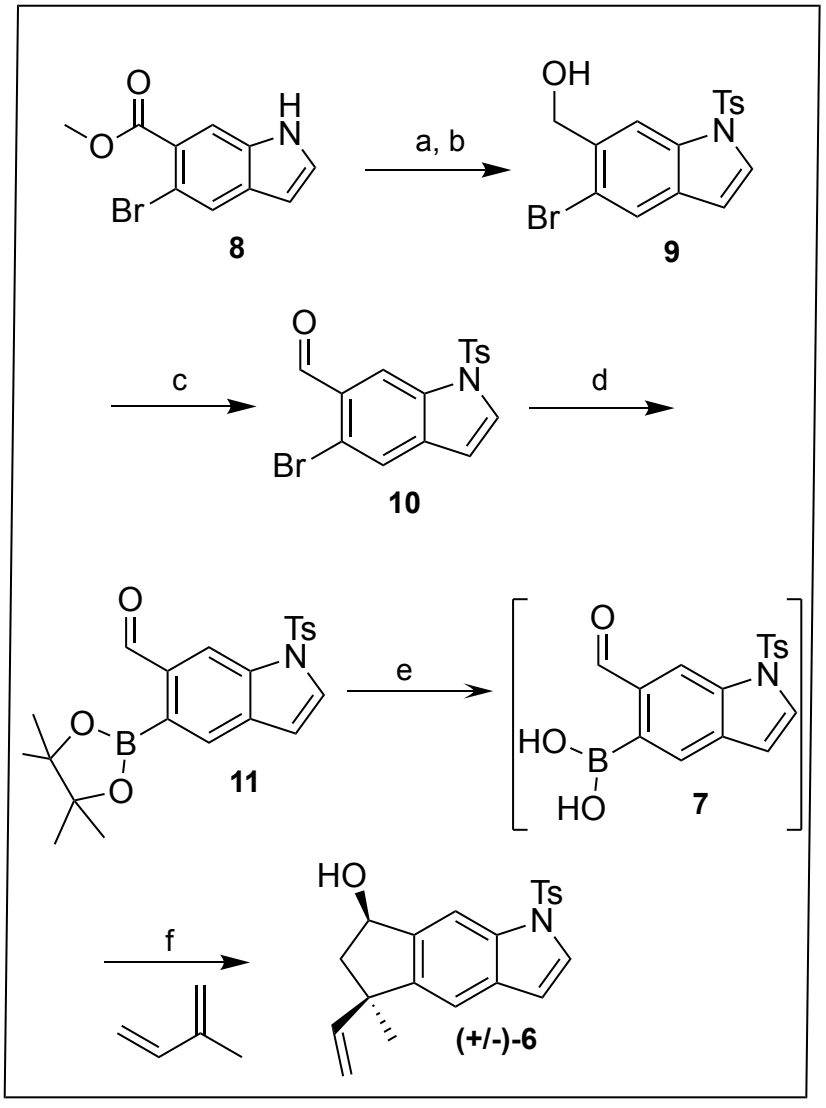

(a) TEBAC ( 0.1 equiv), $\mathrm{NaOH}$ ( 1.75 equiv), $\mathrm{TsCl}$ ( 1.10 equiv), DCM, rt, 2.5 h, 95\%. (b) DIBAL-H (2.0 equiv), DCM, $4.5 \mathrm{~h}, 0{ }^{\circ} \mathrm{C}$ - rt, quant. (c) $\mathrm{MnO}_{2}$ (18.0 equiv), DCM, rt, $5 \mathrm{~h}$, quant. (d) $\mathrm{Pd}(\mathrm{Cl})_{2}(\mathrm{dppf})\left(0.05\right.$ equiv), KOAc (3.0 equiv), $\mathrm{B}_{2}(\text { pin })_{2}$ (1.2 equiv), dioxane, $80{ }^{\circ} \mathrm{C}, 16 \mathrm{~h}, 95 \%$. (e) $\mathrm{H}_{2} \mathrm{O}$ (10.0 equiv), THF:toluene (1:1). (f) $[\mathrm{Ir}(\mathrm{OH})(\mathrm{COD})]_{2}\left(0.05\right.$ equiv), $\mathrm{Et}_{3} \mathrm{~N}$ (1.25 equiv), isoprene (10.0 equiv), THF:toluene ( $1: 1), 80{ }^{\circ} \mathrm{C}, 24 \mathrm{~h}, 94 \%$.

In order to secure indole $\mathbf{6}$ in enantiomerically pure form, enzymatic resolution with lipase $\mathrm{B}$ from Candida antarctica (CALB-Novozym ${ }^{\circledR} 435$ ) known to be very selective for hydrolysis and transesterification of secondary alcohols, particularly in the acetylation of benzylic alcohols as reported by Ferraz and coworkers. $^{18}$ After some experimentation which involved screening some solvents and amount of CALB, we found that by using a toluene/MTBE mixture $(8: 2, \mathrm{~V} / \mathrm{V})$ and increasing the amount of CALB to a $2: 1$ mass ratio compared to the substrate, treatment of benzylic alcohol (+/-)-6 with vinyl acetate provided the corresponding enantiomerically pure acetate $(\boldsymbol{S}, \boldsymbol{S})-12$ (30\% yield) and enantiomerically pure alcohol $(\boldsymbol{R}, \boldsymbol{R})-$ $\mathbf{6}(36 \%$ yield, $>99 \%$ enantiomeric purity as determined by chiral HPLC, see SI). ${ }^{19,20}$

Scheme 3. Enzymatic resolution of benzylic alcohol (+/-)-6.

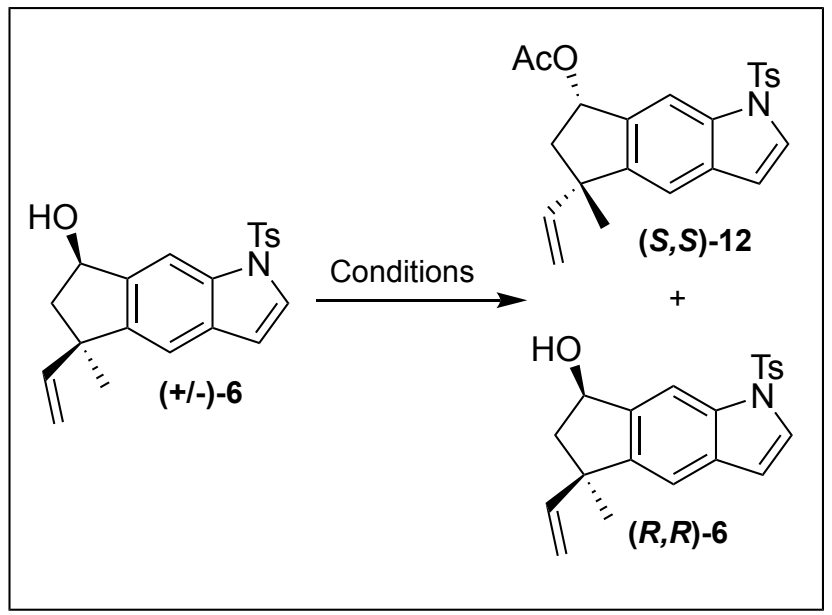

Conditions: vinyl acetate (4.0 equiv), CALB (2;1 mass ratio), toluene/MTBE $(8: 2), 64{ }^{\circ} \mathrm{C}, 34 \mathrm{~h}, 30 \%$ of $(S, S)-12$ and $36 \%$ of $(\boldsymbol{R}, \boldsymbol{R})-\mathbf{6}$ ee $>99 \%$.

In order to complete our synthetic approach to raputindole A (1), it remained the introduction of the isobutenyl side chain and the incorporation of the southern indole moiety. The former was planned to be introduced via allylation of the benzylic carbocation to be derived from $(\boldsymbol{R}, \boldsymbol{R}) \mathbf{- 6}$ with methallyltrimethylsilane which required screening of different Bronsted and Lewis acids. ${ }^{21-23}$ Bismuth tribromide emerged as the best choice as it provided the desired methallyl substituted indole in $69 \%$ yield, albeit in a 2:1 molar ratio (cis:trans isomers). In an attempt to improve the ratio of the trans isomer, the installation of the southern indole moiety previous to the reaction with methallyltrimethylsilane was examined. Although the Heck reaction of 6 with tosylindole 9, prepared according to literature procedure $^{24}$, provided bisindole 17 in $48 \%$ yield, its subsequent reaction with methallyltrimethylsilane promoted by bismuth tribromide provided a complex mixture of products.

Despite the poor stereoselectivity observed in the installation of the isobutenyl side chain, we moved forward with the $2: 1 \mathrm{mix}-$ ture of cis and trans-13a:13b and proceeded to the isomerization of the double bond to convert the exo double bond to the required isobutenyl side chain. Treatment with $p$ - $\mathrm{TsOH}$, in toluene at $80{ }^{\circ} \mathrm{C}$, afforded a $2: 1$ mixture of $\mathbf{1 4 a : 1 4 b}$ in almost quantitative yield. ${ }^{25}$ With the northern and southern moieties secured, the cis/trans mixture of indoles 14a:14b was submitted to the conditions of the Heck reaction employed for $\mathbf{6}$ to provide a 2:1 cis/trans mixture of 16a:16b, in $71 \%$ yield. The removal of both tosyl groups which have served well for the assembly of the key precursor 14a:14b was a challenging undertaking. Initially, we attempted to use TBAF in THF, thioglycolic acid as well as $\mathrm{LiOH}$ in THF but we only observed product degradation. The use of $\mathrm{KOH}$ and $\mathrm{CTAB}$ in $\mathrm{THF}-\mathrm{H}_{2} \mathrm{O}$ under transfer phase catalysis made the deprotection possible, but an inseparable mixture of raputindole $A(\mathbf{1})$ and its monotosyl derivative was obtained ${ }^{26-30}$ Inspection of the ${ }^{1} \mathrm{H}-\mathrm{NMR}$ spectrum of the crude mixture, revealed the formation of a multiplet at $\delta 6.5$ $6.53 \mathrm{ppm}$ which correlates with the one observed in 6-iodo-indole 9 and is suggestive of the southern indole moiety. This conclusion was also corroborated by NOESY analysis of the crude mixture. After extensive experimentation, we found that $\mathrm{NaOH}$ in $\mathrm{THF} / \mathrm{MeOH}$ at $64{ }^{\circ} \mathrm{C}$ was the best condition to remove both tosyl groups providing a mixture of raputindole $\mathrm{A}$ (1) and its $\mathrm{C}$ 6 epimer in $67 \%$ yield which was separated by preparative chiral HPLC (Chiralpak IA column) to afford raputindole A (1) spectroscopically identical to the natural product (see SI). 


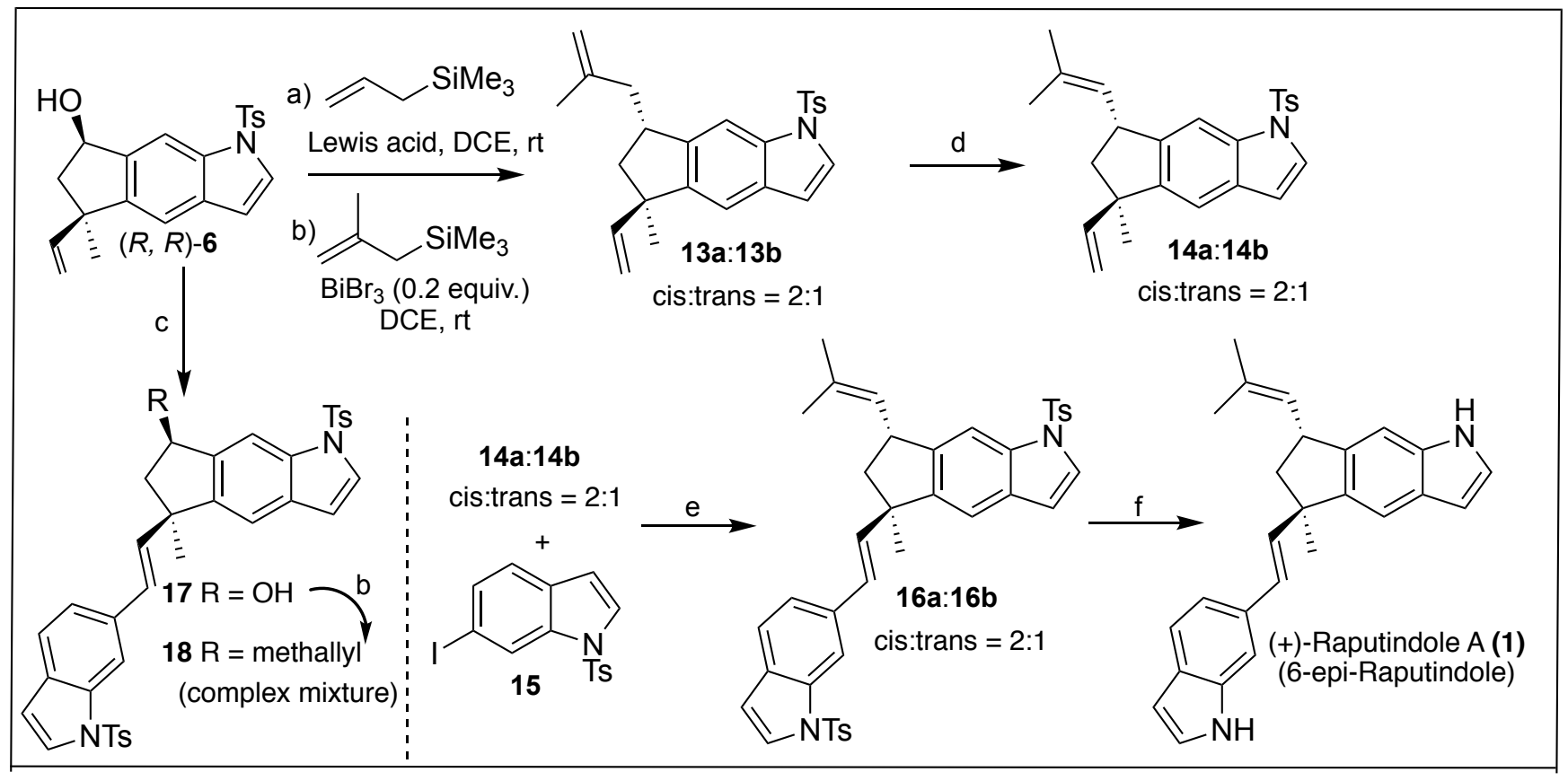

(a) Lewis acid ( 0.2 equiv of $\mathrm{InCl}_{3}, 27 \mathrm{~h}, 52 \%$; 0.1 equiv $\mathrm{BiBr}_{3}, 1,5 \mathrm{~h}, 66 \%$; 0.1 equiv $\mathrm{FeCl}_{3}, 1.5 \mathrm{~h}$, complex mixture), $\mathrm{DCE}$, rt; (b) BiBr 3 (0.2 equiv), DCE, rt, 1 h, 69\% cis:trans (2:1). (c) 14 (2.0 equiv), (5R,7S)-6 (1.0 equiv), $\mathrm{Pd}(\mathrm{OAc})_{2}(0.1$ equiv), $\mathrm{NaOAc}(2.0$ equiv), $n \mathrm{Bu} 4 \mathrm{NBr}(0.2$ equiv), $N, N$-dimethylacetamide: $\mathrm{H}_{2} \mathrm{O}(9: 1), 100{ }^{\circ} \mathrm{C}$, dark, $24 \mathrm{~h}, 48 \%$. (d) TsOH (1.2 equiv), toluene, $80{ }^{\circ} \mathrm{C}$, dark, $4 \mathrm{~h}, 98 \%$. (e) $14 a: 14 b(2.0$ equiv), 15 (1.0 equiv), $\mathrm{Pd}(\mathrm{OAc})_{2}$ ( 0.1 equiv), $\mathrm{NaOAc}\left(2.0\right.$ equiv), $n \mathrm{Bu}_{4} \mathrm{NBr}\left(0.2\right.$ equiv), $N, N$-dimethylacetamide: $\mathrm{H}_{2} \mathrm{O}(9: 1), 100{ }^{\circ} \mathrm{C}$, dark, 24 h, 71\%. (f) $\mathrm{NaOH}$ (10.0 equiv), MeOH:THF (2:1), 67\%, Raputindole (1): 6-epi-Raputindole A (1:2).

In summary, we have accomplished the diastereoselective total synthesis of $(+)$-raputindole A (1) through the stereoselective iridium-catalyzed cyclization and enzymatic resolution which allowed the obtention of the northern part of raputindole A (1), as a 2:1 mixture of cis/trans $\mathbf{1 3 a} / \mathbf{1 3 b}$, after installation of the isobutenyl side chain at C-6. After merging it with 6-iodo-indole 15 (southern part) via Heck reaction and removal of both tosyl groups, (+)-raputindole A (1) was isolated after preparative chiral HPLC separation in 10 steps (LLS) and $10 \%$ overall yield. The versatility of our proposal stems from the possibility to use a chiral version of the iridium catalyst to develop an asymmetric synthesis of raputindole A (1). ${ }^{17}$ Additionally, with minor adaptations our route is amenable to the total synthesis of other members of the raputindole family such as raputindole B (2) and deoxiraputindole C (4) as well as to derivatives thereof to support structure-activity relationship studies.

\section{ASSOCIATED CONTENT}

\section{Supporting Information}

The Supporting Information is available free of charge on the ACS Publications website. Experimental procedures and spectral data for all new compounds (PDF).

\section{AUTHOR INFORMATION}

\section{Corresponding Author}

pilli@iqm.unicamp.br

ORCID

Ronaldo A. Pilli: 0000-0002-5919-7763

Juliana L. L. F. Regueira: 0000-0002-2177-6524

\section{Author Contributions}

LFS conceived the original synthetic proposal.

RAP conceived the revised synthetic approach, supervised the experimental work and the writing of this communication.

JLLFR carried out all the experimental work, wrote the communication and prepared the figures.

Notes

The authors declare no competing financial interest.

\section{ACKNOWLEDGMENT}

Conselho Nacional de Desenvolvimento Científico e Tecnológico (CNPq) (141855/2015-0) for research support and Fundação de Amparo à Pesquisa do Estado de São Paulo (FAPESP) for research grants (\#2016/12096-0 and \#2019/13104-5). The authors wish to thank and dedicate this work to the memory of Professor Luiz Fernando da Silva Jr for his dedication in this project during his life. Thanks for the colleagues from Pilli Group for fruitful discussions that contributed to the final route. Professor Dr. Leandro H. Andrade (USP) for kindly providing enzyme CALB and allow the access to CG-MS equipment. Professor Dr. Fernando Antônio Santos Coelho (UNICAMP) for providing the preparative Chiralpak Colunm. Professor Dr. Helio Alexandre Stefani (USP) for allowed the use of preparative HPLC.

\section{REFERENCES}

1. Vougogiannopoulou, K., Fokialakis, N., Aligiannis, N., Cantrell, C., Skaltsounis, A-L. The Raputindoles: Novel Cyclopentyl Bisindole Alkaloids from Raputia simulans. Org. Lett. 2010, 12, 9, 1908-1911.

2. Rosas, L. V., Veiga, T. A. M., Fernandes, J. B., Vieira, P. C., Da Silva, M. F. G. F. Prenylindole Alkaloids from Raputia praetermissa (Rutaceae) and their Chemosystematic Significance. J. Braz. Chem. Soc. 2011, 22, 7, 1346-1353. Craveiro, M. V., 
3. Tébéka, I. R. M., Longato, G. B., Craveiro, M. V., De Carvalho, J. E., Ruiz, A. L. T. G., Silva, Jr. Luiz F. Total Synthesis of (+)-transTrikentrin A. Chem. Eur. J. 2012, 18, 16890-16901.

4. Chandrasoma N., Pathmanathan S., Buszek, K. R. A practical, multigram synthesis of (+-)-herbindole A, (+-)-herbindole B and (+-)-herbindole $\mathrm{C}$ from a common intermediate via 6,7-indole aryne cycloaddition and $\operatorname{Pd}(0)$-catalyzed cross-coupling reactions. Tetrahedron Lett. 2015, 56, 23, 3507-3510.

5. Xu, M., Gessner, G., Groth, I., Lange, C., Christner, A., Bruhn, T., Deng, Z., Li, X., Heinemann, S. H., Grabley, S., Bringmann, G., Sattler, I., Lin, W. Shearinines D-K, new indole triterpenoids from an endophytic Penicillium sp. (strain HKI0459) with blocking activity on large-conductance calcium-activated potassium channels. Tetrahedron. 2007, 63, 2, 435-444.

6. Ondeyka, J. G., Helms, G. L., Hensens, O. D. Goetz, M. A., Zink, D. L., Tsipouras, A., Shoop, W. L., Slayton, L., Dombrowski, A. W., Polishook, J. D., Ostlind, D. A., Tsou, N. N., Ball, R. G., Singh, S. B. Nodulisporic Acid A, a Novel and Potent Insecticide from a Nodulisporium Sp. Isolation, Structure Determination, and Chemical Transformations. J. Am. Chem. Soc. 1997, 119, 38, 8809-8816.

7. Fernandez, L. S., Buchanan, M. S., Carroll, A. R., Feng, Y. J., Quinn, R. J., Avery, V. M. Flinderoles A-C: antimalarial bis-indole alkaloids from Flindersia species. Org. Lett. 2009, 11, 2, 329-332.

8. Murai, K., Morishita, M., Nakatani, R., Kubo, O., Fujioka, H., Kita, Y. Concise Total Synthesis of (-)-Spongotine A. J. Org. Chem. 2007, 72, 23, 8947-8949.

9. Makangara, J. J., Henry, L., Jonker, S. A., Nkunya, M. H. H. The caulindoles: dimeric prenylindoles from Isolona cauliflora. Phytochemistry. 2004, 65, 2, 227-232.

10. Garg, N. K., Sarpong, R., Stoltz, B. M. The First Total Synthesis of Dragmacidin D. J. Am. Chem. Soc. 2002, 124, 44, 13179-13184.

11. Hill, R. A., Sutherland, A. Hot off the press. Natural Products Reports 2010, 27, 1110-1113.

12. Kock, M., Jones, P. G., Lindel, T. Total Synthesis and Absolute Configuration of Raputindole A. Org. Lett. 2017, 19, 23, 6296-6299.

13. Kock, M., Lindel, T., Diastereosselective Total Synthesis of Raputindole A. Org. Lett. 2018, 20, 17, 5444-5447.

14. Nishimura, T., Yasuhara, Y., Hayashi, T. Iridium-Catalyzed [3 + 2] Annulation of 1,3-Dienes with ortho-Carbonylated Phenylboronic Acids. A Catalytic Process Involving Regioselective 1,2-Addition. J. Am. Chem Soc. 2007, 129, 24, 7506-7507.

15. Han, J., Cui, Z. Wang, J., Liu, Z. Efficient and Mild Iron-Catalyzed Direct Allylation of Benzyl Alcohols and Benzyl Halides with Allyltrimethylsilane. Synthetic Commun. 2009, 40, 2042-2046.

16. Jhang, Y-Y, Fan-Chiang, T-T, Huang, J-M, Hsieh, J-C. CopperCatalyzed Annulation: A Method for the Systematic Synthesis of Phenanthridinium Bromide. Org. Lett. 2016, 18, 5, 1154-1157.

17. Nishimura, T., Yasuhara, Y., Nagaosa, M., Hayashi, T. C2-Symmetric tetrafluorobenzobarrelenes as highly efficient ligands for the iridium-catalyzed asymmetric annulation of 1,3-dienes with 2formylphenylboron reagents. Tetrahedron: Asymmetry 2008, 19, 15, 1778-1783.

18. Ferraz, H. M., Bianco, G. G., Teixeira, C. C., Andrade, L. H., Porto, A. L. M. Enzymatic Resolution of $\alpha$-tetralos by CALB-catalyzed acetylation. Tetrahedron: Asymmetry 2007, 18, 1070-1076.

19. Ribeiro. S. S., Raminelli, C., Porto, A. L. M. Enzymatic Resolution by CALB of Organofluorine Compounds Under Conventional Condition and Microwave Irradiation. J. of Fluorine Chem. 2013, 154, 5359.

20. Bandeira, P. T., Thomas, J. C., de Oliveira, A. R. M., Piovan, L. Lipase-Mediated Kinetic Resolution: An Introductory Approach to Practical Biocatalysis. J. Chem. Educ. 2017, 94, 6, 800-805.

21. Yokozawa, T., Furuhashi, K., Natsume, H. Lewis Acid-catalyzed coupling reactions of allyl trimethylsilyl ethers with allylsilanes. Tetrahedron Lett. 1995, 36, 29, 5243-5246.

22. Nishimoto, Y., Kajioka, M., Saito, T., Yasuda, M., Baba, A. Direct coupling of alcohols with alkenylsilanes catalyzed by indium trichloride or bismuth tribromide. Chem. Comm. 2008, 47, 6396-6398.

23. Reetz, M. T. Lewis Induced $\alpha$-Alkylation of Carbonyl Compounds. Angew. Chem. Int. Ed. 1982, 21, 96-108.

24. Marsch, N., Kock, M., Lindel, T. Study on the synthesis of the cyclopenta[f]indole core of raputindole A. Beilstein J. Org. Chem. 2016, $12,334-342$.

25. Mal, D., Roy, J. A Regioselective facile synthesis of furo[3,4-b]carbazolones: application to the total synthesis of mafaicheenamine $\mathrm{E}$ and claulansine D. Org. Biomol. Chem. 2015, 13, 6344-6352.

26. Charlotte M. Haskins, David W. Knight, Efficient indole N-detosylation using thioglycolate. Tetrahedron Lett. 2004, 45, 599-601.

27. Bajwa, J. S., Chen, G.-P., Prasad, K., Repič, O., Blacklock, T.-J. Deprotection of $\mathrm{N}$-tosylated indoles and related structures using cesium carbonate. Tetrahedron Lett. 2006, 47, 36, 6425-6427.

28. Liu, Y., Shen, L., Prashad, M., Tibbatts, J., Repic, O., Blacklock, T. J. A Green $N$-Detosylation of Indoles and Related Heterocycles Using Phase Transfer Catalysis. Org. Proc. Res. Dev. 2008, 12, 4, 778780 .

29. Liu, W., Lim, J. H., RajanBabu, T. V. Asymmetric Hydrovinylation of Vinylindoles. A Facile Route to Cyclopenta[ $g]$ indole Natural Products (+)-cis-Trinkentrin A and (+)-cis-Trinkentrin B. J. Am. Chem. Soc. 2012, 134, 12, 5496-5499.

30. Santhini, P. V., Krishnan R. A., Babu, S. A., Simethy, B. S., Das, G., Praveen, V. K., Varughese, S., John, J. One-Pot MCR-Oxidation Approach toward Indole-Fused Heteroacenes. J. Org. Chem. 2017, 82, 19, 10537-10548. 